\title{
Constructing a systems psychodynamic wellness model
}

\author{
Authors: \\ Sanchen Henning ${ }^{1}$ \\ Frans Cilliers ${ }^{1}$ \\ Affiliations: \\ ${ }^{1}$ Department of Industrial \\ and Organisational \\ Psychology, University of \\ South Africa, South Africa \\ Correspondence to: \\ Frans Cilliers \\ Email: \\ cillifvn@unisa.ac.za \\ Postal address: \\ PO Box 392, UNISA 0003, \\ South Africa \\ Dates: \\ Received: 31 May 2011 \\ Accepted: 20 Dec. 2011 \\ Published: 23 Mar. 2012 \\ How to cite this article: \\ Henning, S., \& Cilliers, F. \\ (2012). Constructing a \\ systems psychodynamic \\ wellness model. SA Journal \\ of Industrial Psychology/SA \\ Tydskrif vir Bedryfsielkunde, \\ 38(2), Art. \#989, 9 pages. \\ http://dx.doi.org/10.4102/ \\ sajip.v38i2.989
}

(C) 2012. The Authors

Licensee: AOSIS

OpenJournals. This work

is licensed under the

Creative Commons

Attribution License.
Orientation: The researchers constructed a Systems Psychodynamic Wellness Model (SPWM) by merging theory and concepts from systems psychodynamics and positive psychology. They then refined the model for application in organisations during a Listening Post (LP) that comprised experienced subject experts.

Research purpose: The purpose of the research was to construct and refine the SPWM in order to understand psychological wellness at the individual, group and organisational levels.

Motivation for the study: There is no psychological wellness model that integrates the principles of systems psychodynamics and positive psychology. Systems psychodynamics traditionally focuses on so-called negative behaviour whilst positive psychology tends to idealise positive behaviour. This research tried to merge these views in order to apply them to individual, group and organisational behaviour.

Research design, approach and method: The researchers used qualitative, descriptive and conceptual research. They conducted an in-depth literature study to construct the model. They then refined it using the LP.

Main findings: The researchers identified 39 themes. They categorised them into three different levels. Three first-level themes emerged as the highest level of integration: identity, hope and love. The nine second-level themes each consisted of three more themes. They were less complex and abstract than the first-level themes. The least complex 27 third-level themes followed.

Practical/managerial implications: One can apply the SPWM as a qualitative diagnostic tool for understanding individual, group and organisational wellness and for consulting on systemic wellness.

Contribution/value-add: The SPWM offers a model for understanding individual, group and organisational wellness and for consulting on systemic wellness.

\section{Introduction}

Kets de Vries (2007) stated that 'wellness' seems typical of the Zeitgeist of our age. One can describe it as a preoccupation with health, wealth and happiness. The key focus of the current study was to explore the concept of psychological wellness and provide insights that go beyond trendy buzzwords. The researchers envisaged that consultants would apply the deeper insights they gained from the research to the practice of consulting psychology.

The psychological paradigms of this study were systems psychodynamics and positive psychology. Throughout the research, the researchers highlighted the emerging themes in an appropriate colour (see Figure 1), indicating to which level of analysis the theme belongs in the final psychological wellness model. A brief overview of the two paradigms follows.

\section{Systems psychodynamic theory}

The systems psychodynamic paradigm evolved at the Tavistock Institute in the United Kingdom in the 1950s and 1960s (Miller, 1993). It is a combination of the 'working outside in' (systems) perspective and the 'working inside out' (psychodynamic) perspective (Czander, 1996). The two different perspectives merge to provide a unique framework because it integrates the concepts of systems thinking and psychoanalysis to understand the unconscious processes in people, groups, organisations and societies better (Gould, Stapley \& Stein, 2004).

From a systems psychodynamic perspective, wellness is a relational concept. Object relation theory postulates that the periods of loving care must exceed those of frustration and deprivation during childhood for wellness to develop and be sustained (Klein, 1975). If all goes relatively 
well and the child experiences a budding faith in primary caretakers, the child eventually develops the ability and courage to integrate the opposing feelings of love and hate (Klein, 1975).

Traditional psychological approaches reduced human beings to a bundle of sensations, drives, innate and learned reactions. In contrast to this mechanistic approach, systems theory proposes that humans link inextricably to the greater web of life. One cannot study them in isolation. The universe is a hierarchy of systems, where each higher level of a system comprises systems at lower levels (Keeney, 1983). One can regard the psychological wellness of any person, group or organisation as an open system, consisting of numerous subsystems that interact across different system boundaries (Keeney, 1983). According to O'Connor and Lubin (1990), psychological wellness is the result of constant interpersonal (between people) and intrapersonal (within a person) change and variety.

\section{Positive psychology}

Positive psychology is a sub-discipline of psychology that studies the nature, manifestations and ways of improving positive subjective experiences that link to strengths and virtues (Snyder \& Lopez, 2005). It aims to change the focus of theory and practise in some fields of psychology from a preoccupation with disease and healing to well-being and improving strengths and virtues. Treatment is not just fixing what is wrong. It is also building what is right. Psychology is not just about illness or health. It is also about work, education, insight, love, growth and play. This perspective implies an active human that is constantly adapting to the environment to ensure wellness (Lopez, 2008).

One can regard humanistic psychology theorists as the founders of positive psychology (Cilliers \& May, 2010). As a field of study, it recognises the importance of learning and optimistically focuses on a person's future rather than on the past. It is concerned with concepts like love, hope, creativity, values, meaning and self-actualisation. Positive psychology encourages buffering strengths like courage, interpersonal skill, curiosity, the capacity for pleasure, future-mindedness and, from psychoanalytic theory, a mature identity (Peterson \& Seligman, 2006).

\section{Research purpose}

According to Els and de la Rey (2006), there is a growing trend in organisations world-wide to acknowledge the importance of the so-called human factor as various disciplines highlight the importance of a 'good life', work-life balance and of attending to the total wellness of employees. At the same time organisational consultants are increasingly expressing their need to understand the deeper levels of individual, group and organisational behaviour that manifest 'below the surface' (Huffington, Armstrong, Halton, Hoyle \& Pooley, 2004) and to address them. Nevertheless, theorists have never integrated these two perspectives into a model that aims to understand the deeper levels of wellness behaviour and its effects at the individual, group and organisational levels. The purpose of this study was to construct such an integrative model, called the Systems Psychodynamic Wellness Model, and to refine the model in an experiential event, namely a LP, that comprised experienced subject experts.

\section{Trends from the research literature}

Scholars from different psychological paradigms attempted to define psychological wellness. They contributed to several theories on the topic. Freud $(1947$, p.31) believed that one must change unconscious material into conscious material before a person will experience wellness: 'Where Id is there Ego shall be'. He went on to propose that having work to do and someone to love is necessary for a person to be well adjusted. For Jung (1950), one achieves individual wellness through individuation and self-realisation. Erikson (1968) remarked that, to understand how a person grows towards wellness, it is necessary to remember the epigenetic principle that derives from the growth of organisms in vitro:

...this principle states that anything that grows has a ground plan, and that out of this ground plan the parts arise, each part having its time of special ascendancy, until all parts have arisen to form a functioning whole. (p. 52)

To Erikson (1968), basic trust is the cornerstone of a welladjusted adult personality. Antonovsky (1987), the founder of the 'salutogenesis' paradigm, described wellness as an 'ease-disease' continuum. Any person, group or organisation at any given time can oscillate between the two extremes on the continuum. The psychoanalyst Janov (1991) stated that the hallmark of psychological wellness is a person's ability to be satisfied with life:

The neurotic is often dissatisfied with almost everything. Such an individual is missing something, so there is never enough money, security, love, sex, power, prestige or fame. Just feeling satisfied with one's life is an enormous achievement. (p. 316)

He went on to say that a person, who is psychologically well, is authentic and naturally cares because such a person has access to feelings and can really empathise with others.

Strümpfer (1995), as well as Wissing and Van Eeden (1997), proposed that wellness is a dynamic construct on a continuum of extremes where optimal wellness is on the one pole of the continuum and illness is on the other. It is at this point that the researchers challenged the idea of a linear wellness continuum in favour of a systems approach. This describes psychological wellness using concepts like circularity, interdependency and interrelationship. The emphasis shifted from a deterministic understanding of linear causality towards a holistic understanding of context, complexities and paradox.

The researchers introduced chaos theory into the study as a branch of systems thinking. The old Newtonian scientists had an image of the world that one can compare to a big clock (Wilber, 2000). Knowledge about how the clock worked would enable one to predict what could happen at any point 
in time. They believed in certainties and not probabilities. The modern science of chaos shows that causality does not apply everywhere. Chaos seems to be the creative force behind the emergence of new life forms. It appears in texts from Asian and Egyptian mythology (Butz, 1997). People often use 'chaos' in a negative sense and associate it with incompetence. However, chaos theory assumes that chaos exists within limits. One can describe orderly chaos as 'bounded instability'. It sustains all forms of life through constant change and variety (Stacey, 2003). Chaos theory offers a new way of looking at options for responding to unstable conditions. This new understanding does not anticipate disintegration and panic because of a lack of structure, but is open to the emergence of novel and more creative outputs. In this sense, the constant change and variety makes hope a central theme in chaos theory. For the purpose of this research, chaos theory was valuable as a metaphor to describe the complexity embedded in psychological wellness in a person, group or organisation.

Glass and Mackey (1988) stated that the world is not a gigantic, mechanical clock that is merely winding down, but a game of chance and choice. It allows room for free will, individuality and unpredictable creativity through selforganising properties. The process of flux is an intrinsic part of natural processes in all living systems. Bounded instability is necessary for flexibility, innovation and the capacity for finding new solutions in rapidly changing and unpredictable situations (Stacey, 2003). In laymen's terms, one can conclude that there is no growth without a little chaos.

Jung (1960) held that the tension of opposites contains wellness or wholeness, like a swinging pendulum, and that one cannot find it in a static condition:

When the opposites unite, all energy ceases: there is no more flow. The waterfall has plunged to its full depth in that torrent of nuptial joy and longing; now only a stagnant pool remains, without wave or current. (p. 467)

All life is a marriage of opposites and true wellness is a form of wholeness (Bradshaw, 1992). Holistic thinking is central to a systems perspective. Changes in one part lead to changes to all parts and to the system itself. One cannot understand the system as a whole by analysing its separate parts: 'The essential properties of a system are lost when it is taken apart; for example a disassembled automobile does not transport and a disassembled person does not live' (Patton, 1990, p. 79).

Bateson (2000) stated that there is 'a pattern that connects' living systems to one another, (that is, similar systemic concepts repeat in different contexts). The brilliant colours and shapes of fractal geometry illustrate this idea. Fractal geometry is a feature of chaos theory. It provides the graphic 'container' for the theoretical content of the model. It is also the 'pattern that connects' and is evident in human behaviour.

\section{The fractal geometry of human behaviour}

Chaos theory offers an organic view of human life and a philosophy of hope (Patton, 1990) because of the underlying assumptions of continuous and rapid change, chance and endless variety. Therefore, it provides an important parallel with positive psychology, where the adaptive potential of humans, groups and organisations, their growth and concepts, like creativity and variety of experiences, are central (Snyder \& Lopez, 2005).

Gilgen (1995, p. 182) stated that hope is the understanding that, because flux underlies all that is, nothing is unchangeable or fixed: '...the will to happiness is the ultimate strange attractor in human experience' and '...the universe in its unfolding will never stop at any one informational level'. The implication is that humans have the freedom to choose and creatively weave themselves and their universe. Therefore, hope is inherent in chaos theory as people, groups and organisations graph their own existence randomly and unpredictably through chance and choice.

Another characteristic of fractals is the uniqueness of the pattern of each individual fractal as it presents an everevolving identity (Mandelbrot, 2005). This reflects the evolving identity of humans, groups and organisations. They all have their own developmental trajectory that gives rise to a special and unique identity.

A third characteristic of fractals is the evolving 'patterns that connect' (Bateson, 2000), implying some form of relatedness between subsystems within a bigger system. Fractals are patterns within patterns within patterns that develop over time, ad infinitum. People are parts of groups that form parts of organisations, which again form parts of a greater society. It is a continuous process of increasing complexity. In human relationships, the 'pattern that connects' may become what Klein (1975) referred to as object relations from the psychodynamic paradigm. Here, patterns of attachment, that is, feelings of love and hate for 'objects' are central. Humans, as living fractals, co-create each other through their relatedness to each other. Love makes psychological wellness attainable to all (Janov, 1991). Psychological wellness is complex and evolving. It is always in process and is never a static state to which one should aspire. The freedom to choose and the desire for happiness are central to psychological wellness:

Living and choosing is an aesthetic process; so a beautiful life is a truthful life lived out of one's happiness, one's open-ended consonance with the implicit order's subtle promptings... (Gilgen 1995, p. 183)

\section{Core research problem and specific research objectives}

Els and De la Rey (2006) believed that existing conceptual foundations, models and theories of wellness had a limited effect on wellness research. It seems that the current wellness research seldom led to the phrasing of vital research questions or to the determination of programme contents, their design and development in meaningful ways. The primary research objective was to construct a psychological wellness model that merges the theories and concepts of systems psychodynamics with those of positive psychology to apply at the individual, group and organisational levels. 
The secondary research objective was to refine the model by using a LP that comprised experienced subject experts.

\section{The potential value-add of the study}

The potential value-add of the study is that consultants can use the SPWM as a qualitative diagnostic tool for understanding individual, group and organisational wellness and for consulting on systemic wellness. It includes various organisational development inputs, like executive and leadership coaching for people and teams, team building and change management. In addition, one can apply the SPWM to the market research environment because its wellness concepts might reflect the social dynamics of a particular social context.

\section{What will follow}

The next sections of the article describe the research design, the graphic construction of the model, the findings and discussion of the findings. Finally, the researchers made recommendations for future research.

\section{Research design \\ Research approach}

The researchers used a qualitative research approach. They framed it as a non-numeric examination and interpretation of observations to discover underlying meanings and patterns of relationships (Babbie, 2007) in psychological wellness. The research was descriptive and conceptual in nature (Denzin $\&$ Lincoln, 2005). The researchers approached the study from an artistic and metaphoric perspective and described it as a process with phases that connect to different forms of behaviours, their interpretation and presentation.

\section{Research strategy}

The strategy consisted of two phases. Phase 1 comprised an extensive literature study and several content analyses to identify patterns of psychological wellness within systems psychodynamics and positive psychology. The researchers explored the potential of fractal geometry as the graphic design for the model and constructed the model theoretically. Phase 2 comprised administering the LP and refining the SPWM.

\section{Research method}

\section{Research setting}

The researchers set the study within the organisational psychology fraternity, especially practitioners familiar with systems psychodynamics and positive psychology.

\section{Entrée and establishing researcher roles}

The first researcher had two distinct roles. The first was to be the qualitative researcher, to construct the SPWM, to analyse the data and refine the model (Terre Blanche, Durrheim \&
Painter, 2006). The second was to be a participant observer (Brewerton \& Millward, 2004) during the LP, to witness, describe, record and make sense of the data whilst being part of it (Clarke \& Hoggett, 2009). The second researcher was the research supervisor (Clarke \& Hoggett, 2009) and convenor of the LP. Both researchers used the orientation of self as the instrument of analysis (McCormick \& White, 2000). Both are psychologists with doctorate degrees and know about positive psychology. They both have specific training, theoretical knowledge and experience in systems psychodynamic consulting and research that conforms to the requirements that Brunner, Nutkevitch and Sher, (2006) set.

\section{Sampling}

The first researcher used purposive sampling of the literature (in phase 1) and the participants (in phase 2) to select information-rich data for an in-depth study (Fisher, 2006). In phase 2, the second researcher selected 15 participants based on their substantial local or global group relations and systems psychodynamic consulting experience.

\section{Data collection methods}

In phase 1, the first researcher analysed the literature on psychological wellness from the systems psychodynamics and positive psychology perspectives and constructed the SPWM. In phase 2, the second researcher administered the LP. The LP is a systems psychodynamic organisational consultancy method (Gould, Stapley \& Stein, 2004; Neumann, Kellner \& Dawson-Shepherd, 1997) that the Organisation for Promoting Understanding of Society (OPUS) developed (Stapley, 2006a; 2006b). It focuses on a specific matter that has an unstructured design (Stapley \& Collie, 2005). Consultants use the first hour to process a set question and a second to formulate hypotheses based on the previous processing (Dartington, 2000).

A system psycho-dynamically informed convenor controls the time boundaries firmly, introduces and closes the event. The quality of the LP depends on the convenor's ability to allow participants to share their experiences in a contained space without judgement, memory or desire (Czander, 1997) and to manage the boundaries between the two roles of convenor and member. The second researcher invited the selected participants to attend the LP. The second researcher presented the SPWM to them and set the question: 'does the SPWM make sense as a conceptual model for understanding individual, group and organisation wellness?' To allow the 15 participants to process the material freely, the second researcher administered the LP in two sessions. One had eight and the other seven participants.

\section{Recording of data}

The researchers followed the guidelines of Hinshelwood and Skogstad (2005). These were to make an audio recording of the LP with the consent of the participants and to take descriptive field notes during and after the event. 


\section{Data analyses}

Bateson (2000) referred to the 'drawing of distinctions' to describe how a person constructs reality. One can describe developing the theoretical content of the model as the continuous 'drawing of distinctions' from the literature on psychological wellness. Pirsig (1987) used sorting sand as a metaphor for the way humans draw distinctions or gain knowledge from their world:

We take a handful of sand from the endless landscape of awareness around us and call that handful of sand the world. The handful of sand looks uniform at first, but the longer we look at it the more diverse we find it to be. We form the sand into separate piles on the basis of this similarity and dissimilarity. Shades of colour in different piles — sizes in different piles subtypes of colours in different piles, and so on, and on, and on. (p. 75)

This metaphor appropriately describes what the first researcher experienced when she analysed the literature. During phase 1, using several levels of content analyses (Miles \& Huberman, 1994) was the method she chose to 'map' the psychological wellness territory. From the literature on systems psychodynamics and positive psychology, different themes emerged. She integrated them into three different levels of analysis. Each level categorised themes at a progressively higher level of abstraction. In phase 2, the researchers used the LP data to confirm the themes, their progressive nature and to refine the definitions of some of the themes.

\section{Strategies employed to ensure quality data}

The knowledge one gains from research is only a description of reality and is not reality in itself (Bateson, 2000). The first researcher was aware of her own subjective reality and ensured that self-reflection occurred through continuous discussion with others and by diarising her experiences. Bogdan and Bilken (2003) referred to self-reflection as a strategy to improve researcher credibility. Fisher (2006) referred to witness validity and touch point validity as ways of improving the trustworthiness of qualitative data. Witness validity confirms that readers of the data (in this research, the participants of the LP) and findings reach conclusions that are similar to those the researchers do. Touch point validity confirms that the findings connect with theory and with other studies productively. Researchers affirm, reconcile and expand previous understandings of the topic (Fisher, 2006, p. 6). The researchers were careful to remain within the chosen paradigms throughout the research.

\section{Reporting}

Firstly, the researchers reported the findings of the multilevel content analysis. They then completed the graphic construction of the wellness model (the Sierpinski Triangle). Finally, they integrated them in the System Psychodynamic Wellness Triangle.

\section{Findings}

Thirty-nine themes emerged from the literature review and created patterns (three first-level themes) within patterns (nine second-level themes) and within patterns (27 third-level themes). Each of the three first-level themes consisted of three second-level themes, which again consisted of three thirdlevel themes. Figure 1 illustrates them. The first-level analysis describes three themes at the highest level of abstraction. The second-level analysis consists of nine second-level themes, which are less abstract and complex. The third-level analysis consists of 27 themes that are the most concrete. One can describe them as behavioural manifestations.

\section{First-level analysis}

\section{Theme 1: Identity}

Identity is all about becoming and being someone and answers the question 'who am I?' It aims to explain how people, groups and organisations develop an identity, a unique personality, and how they maintain it:

- second-level analysis, theme 1: the sources of self

- third-level analysis, theme 1: evolution of self

- third-level analysis, theme 2: self-image

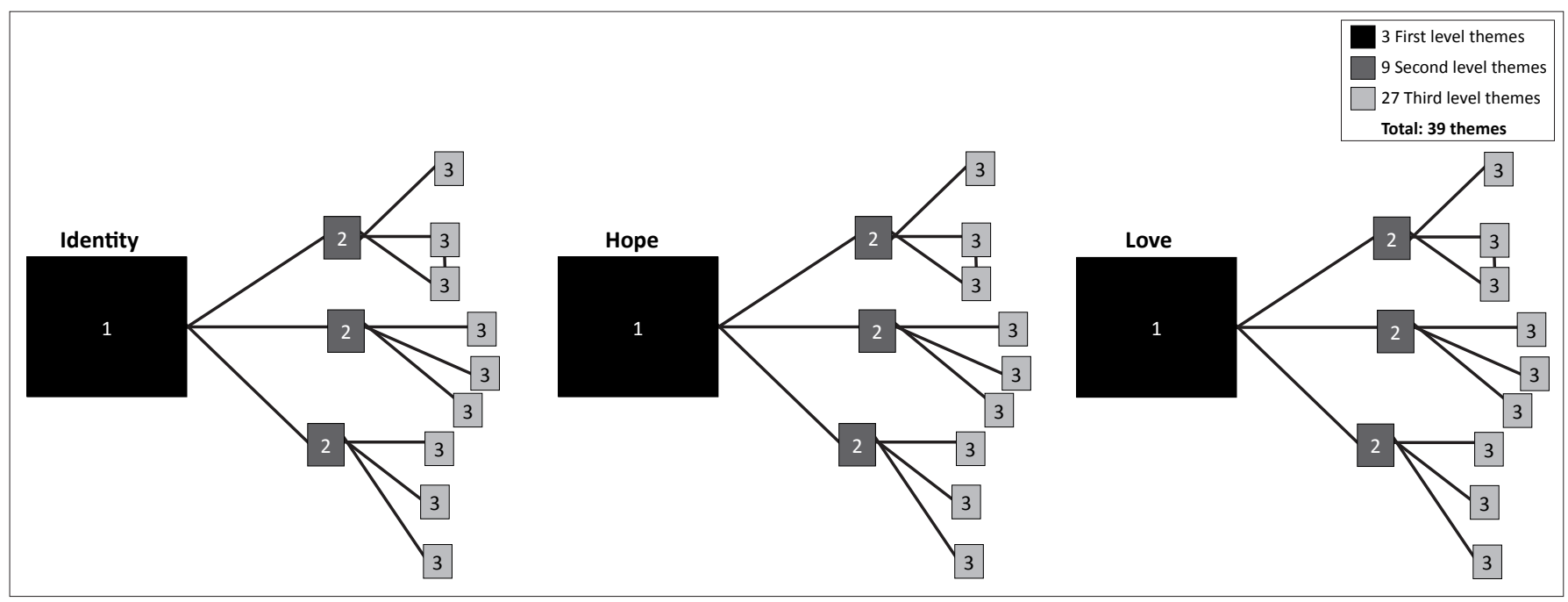

FIGURE 1: Multi-level content analysis. 
- third-level analysis, theme 3: narcissism

- second-level analysis, theme 2: ego

- third-level analysis, theme 1: ego structure

- third-level analysis, theme 2: ego ideal

- third-level analysis, theme 3: ego defences

- second-level analysis, theme 3: boundary management

- third-level analysis, theme 1: space boundaries

- third-level analysis, theme 2: task boundaries

- third-level analysis, theme 3: time boundaries.

\section{Theme 2: Hope}

Hope addresses the question 'why am I?' Themes that explore the search for meaning and direction for the future of people, groups and organisations are:

- second-level analysis, theme 1: wisdom

- third-level analysis, theme 1: open-mindedness

- third-level analysis, theme 2: curiosity

- third-level analysis, theme 3: creativity

- second-level analysis, theme 2: meaning

- third-level analysis, theme 1: attachment

- third-level analysis, theme 2: goal-seeking

- third-level analysis, theme 3: authenticity

- second-level analysis, theme 3: paradox

- third-level analysis, theme 1: reparation

- third-level analysis, theme 2: mastery

- third-level analysis, theme 3: optimism.

\section{Theme 3: Love}

Love refers to the question 'how do I relate?' It illustrates relational aspects, particularly one's relationship with oneself and with others:

- second-level analysis, theme 1: mirror gazing - self

- third-level analysis, theme 1: self-knowledge

- third-level analysis, theme 2: self-acceptance

- third-level analysis, theme 3: self-actualisation

- second-level analysis, theme 2: window watching - others

- third-level analysis, theme 1: social acceptance

- third-level analysis, theme 2: social integration

- third-level analysis, theme 3: social actualisation

- second-level analysis, theme 3: transcendence

- third-level analysis, theme 1: beyond boundaries

- third-level analysis, theme 2: transformation

- third-level analysis, theme 3: aesthetics.

In summary, the researchers used a hierarchical approach to construct the model. Third-level themes are not disjointed fragments but form a network of mutual interactive themes, each valid in their own right. The 39 themes are all relevant on individual, group and organisational levels of consultation. Henning (2009) discusses them in detail.

\section{Graphic construction of the Systems Pychodynamic Wellness Model: fractal geometry}

Mandelbrot (2005) coined the term 'fractal geometry' from the Latin fractua, which means 'irregular'. Fractal geometry is a visual way of understanding the natural sciences and a way of showing how things often display the same structure when one looks at the same things on bigger and bigger or smaller and smaller scales. The whole is also always within each part and each part is also the whole. One finds patterns repeatedly at descending scales, so that their parts, at any scale, are similar in shape to the whole. One can see self-similarity in cauliflowers, snowflakes, Gothic arches in European cathedrals, branches of lightning, leitmotifs in operas, the distribution of galaxies, weather patterns and coastlines.

\section{The Sierpinski Triangle}

Symbols are universal and pervade all cultures as they resonate with the fundamental aspects of human nature (Jung, 1950). They speak of shared wisdom whose truths we recognise but can never quite put into words. The triangle is the universal symbol of change and transformation. Religion, myth, folk tales, science and art tenaciously reiterate the importance of trinities because of their deep roots in every part of us: 'They have powerful psychological effects on us because the tripartite universe connects us with its archetypal root within us' (Schneider, 1994, p. 144). The Sierpinski Triangle is a fractal named after Sierpinski, who described it in 1915 (Mandelbrot, 2005).

It offers a graphic design whilst reflecting the process of multilevel content analysis. In addition, it contained all 39 themes, as they emerged from the data, in one complete structure. It is one of the most basic examples of self-similar sets. That is, it is a mathematically generated pattern that one can reproduce at any magnification or reduction (see Figure 2).The geometric simplicity of the triangle makes it an appropriate symbol with which to construct a complex theoretical model. The original triangle consisted of a hierarchical set of triangles, which

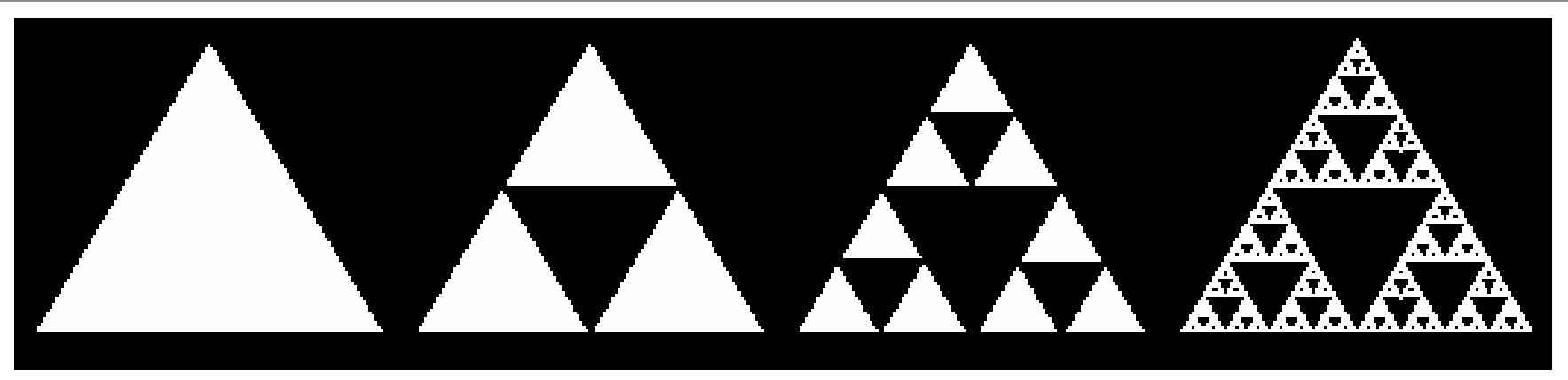

FIGURE 2: The Sierpinski Triangle. 
again consists of another set of triangles. Mathematically, the process can keep on generating triangles at deeper and deeper levels, ad infinitum.

Sierpinski (Mandelbrot, 2005) referred to the original, white triangle as the 'generator triangle' because it repetitively generates, according to fractal geometry, more similar shapes or, in this case, more triangles. Similarly, the 'generator' theme of 'psychological wellness' generated qualitative themes within themes within themes, each theme describing a specific aspect of the original theme. The complete structure comprises 40 triangles. Jung (1950) noted that the number 40 symbolises 'wholeness', 'totality' and 'completeness'.

Thirty-nine themes emerged from this research. Mathematically, one can calculate the number of themes as follows: $(3 \times 1)+(3 \times 3)+(3 \times 3 \times 3)=39$. The 40 th triangle gives the name of the psychological wellness model, which is the Systems Psychodynamic Wellness Triangle. Figure 3 below illustrates it.

\section{Discussion}

The primary research objective was to construct the Systems Psychodynamic Wellness Model and to refine the model conceptually in order to understand psychological wellness at the individual, group and organisational levels. Existing models are mostly insensitive to the systemic properties of living systems. People, groups and organisations are systems within systems within systems that are connected and interdependent. One needs to explore them in context. From a systems perspective, individual parts of any living system are important and one cannot disregard them. However, it

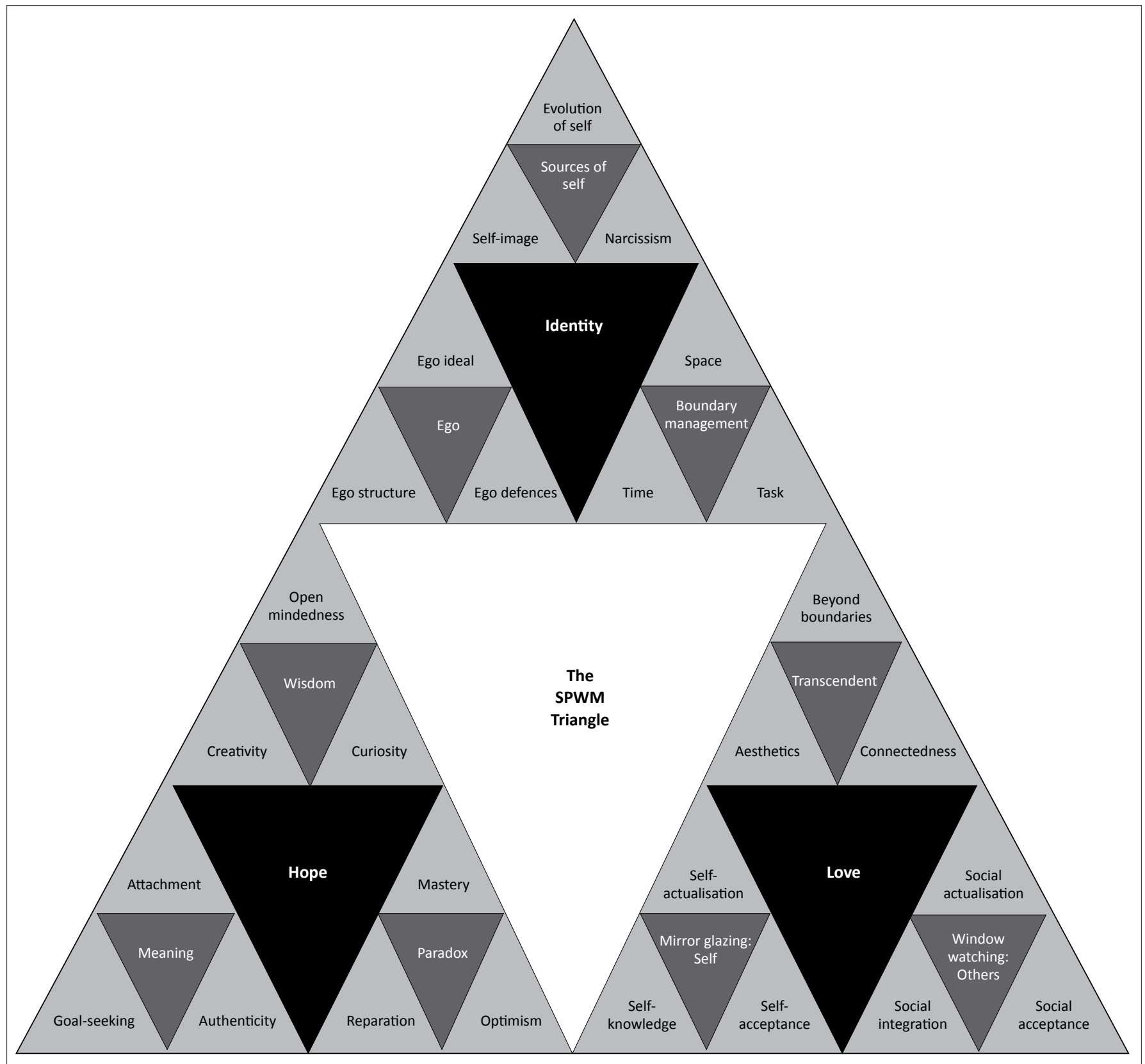

FIGURE 3: The Systems Psychodynamic Wellness Triangle. 
is understanding the relationships between the parts of the system and how they fit into the whole that enables deeper insights into the phenomena.

The SPWM Triangle integrates systems psychodynamic thinking and positive psychology, thereby offering a more holistic and optimistic perspective for studying human behaviour as opposed to the traditional, mechanistic perspectives that focused mainly on disease and pathology. The researchers achieved the primary research objective in constructing the SPWM Triangle, where the first-, secondand third-level themes display a logical flow from simple to complex.

The theoretical paradigms (systems psychodynamics and positive psychology) contained the themes that the researchers identified to describe psychological wellness at individual, group and organisational levels. The firstlevel analysis themes have the highest level of abstraction. The three first-level themes reflect this integration. Identity is a central concept in systems psychodynamics whilst hope and love are inherent to positive psychology. In the graphic design of the model, a fractal called the Sierpinski Triangle provided the container for the emerging themes. It is significant that the themes of hope and love are at the left and right base corners of the triangle, whilst identity is at the top corner. These symbolic positions show that identity is a product of hope and love.

This research challenged the linear wellness continuum (Wissing \& Van Eeden, 1997), where illness and wellness are at the opposite extremes, in favour of a systems approach. One expects psychological wellness and the wellness of any living system in conditions where there is change and variety, a tendency to move towards greater differentiation, detail, complexity, paradox and bounded instability (Stacey, 2003). In addition, one can state that positive psychology is a transitional object (Winnicot, 1951). It focuses on the easedisease model toward an integrated system psychodynamic model of psychological wellness.

Von Bertalanffy (1973) stated that life is not a comfortable settling down in pre-ordained grooves of being. Instead, it inexorably drives all living systems towards higher forms of existence. It is along these lines of systemic thinking that a new model or image of man as an 'active personality system' seems to emerge. One can see systems thinking as an inherently hopeful theory because it describes dynamic, ever-changing systems and not closed, deterministic systems that cannot learn and adapt. Like living fractals, people, groups and organisations evolve. How well they evolve, that is, who they become, why they became and how they relate, is a matter of chance and many choices over a period.

The researchers confirmed witness and touch point validity (Fisher, 2006). It led them to conclude that the SPW makes sense as a systemic wellness model that organisations can use. They acknowledged the potential of the model as a diagnostic tool in organisational psychology and for managing customer relationships.

\section{Conclusions}

The researchers concluded that one could use the SPW Triangle as a conceptual qualitative diagnostic tool for understanding individual, group and organisational wellness. One can also use the model in a market research environment because its wellness concepts could reflect the social dynamics of a particular social context. Knowing what matters to customers, and taking care to align their needs to strategies, will enable targeted advertising and communication initiatives.

\section{Recommendations}

The researchers recommend that consultants use the SPWM as 'a model in the mind' (Armstrong, 2005) to guide their discussions and generate interactive communication when they are working with people, groups or organisations. They also recommend that researchers validate the model in qualitative and quantitative research in various organisational settings, like individual and team coaching.

\section{Possible limitations of the study}

The SPW Triangle reflects significant complexity around the topic of psychological wellness. However, one can never capture all of its complexity. The descriptive nature of the research leads to many questions that the researchers could not answer in the current research. Although the systems psychodynamic literature is substantial, the availability of literature that explores psychological wellness from this paradigm is extremely limited. The conceptual meaningfulness of the model depends to some extent on the user's understanding of the systems psychodynamic paradigm and concepts from positive psychology. The researchers have completed the conceptualisation of the model. However, they have not explored the operational aspects of the model.

\section{Suggestions for further research}

Future research possibilities include structural equation modelling to construct a quantitative model. This could lead to identifying key drivers that could affect the overall psychological wellness of a system. They might enable business leaders to spend money more wisely on targeted interventions, thereby improving their return on investments. The SPW Triangle could assist businesses to transform customer service transactions into customer service engagements. They could design a unique customer relationship management questionnaire using sound theoretical principles. They could also use it for customer research to explore customers' service expectations as well as the quality of their relationships with a specific brand. 


\section{Acknowledgements Competing interests}

The authors declare that they have no financial or personal relationship(s) that may have inappropriately influenced them when they wrote this paper.

\section{Authors' contributions}

Both authors planned the research project. S.H. (University of South Africa) conducted the literature review and the empirical study. During the LP, F.C. (University of South Africa) was the convenor and S.H. (University of South Africa) was the participant observer. F.C. (University of South Africa) was also the supervisor for the whole research project.

\section{References}

Antonovsky, A. (1987). Unraveling the mystery of health: How people manage stress and stay well. San Francisco: Jossey-Bass.

Armstrong, D. (2005). Organisation in the mind. Psychoanalysis, group relations and organisational consultancy. London: Karnac.

Babbie, E. (2007). The Practice of Social Research. (7th edn.). Belmont: Wadsworth. Bateson, G. (2000). Steps to an ecology of mind. London: University of Chicago Press.

Bogdan, R.C., \& Bilken, S. (2003). Qualitative research for education: An introduction to theory and method. Boston: Alyn \& Bacon.

Bradshaw, J. (1992). Home Coming: Reclaiming and championing your inner child. London: Bantam Doubleday Dell.

Brewerton, P., \& Millward, L. (2004). Organisational research methods. A guide for students and researchers. London: Sage.

Brunner, L.D., Nutkevitch, A., \& Sher, M. (2006). Group relations conferences: Reviewing and exploring theory, design, role-taking and application. London: Karnac.

Butz, M.R. (1997). Chaos and complexity: implications for psychological theory and practice. Washington, DC: Talyor \& Francis.

Cilliers, F., \& May, M. (2010). The popularisation of Positive Psychology as a defence against behavioural complexity in research and organisations. South African Journal of Industrial Psychology, 36(2), Art. \#917, 10 pages. http://dx.doi. org/:10.4102/sajip.v36i2.917.

Cilliers, F., \& Smit, B. (2006). A systems psychodynamic interpretation of South African diversity dynamics: A comparative study. South African Journal of Labour Relations, 30(2), 5-18.

Clarke, S., \& Hoggett, P. (2009). Researching beneath the surface. Psycho-social research methods in practice. London: Karnac.

Czander, W.M. (1997). The psychodynamics of work and organisations: Theory and application. New York: Guilford Press.

Dartington, T. (2000). The pre-occupation of the citizen - reflections from the OPUS Listening Posts. Organisational and Social Dynamics, 1, 94-112.

Denzin, N.K., \& Lincoln, Y.S. (2005). The Sage handbook of qualitative research. London: Sage publications.

Els, D.A., \& De la Rey, R.P. (2006). Developing a holistic wellness model. South African Journal of Human Resource Management, 4(2), 46-56.

Erikson, E.H. (1968). Identity and the life cycle. New York: International Universities Press.

Fisher, C.T. (2006). Qualitative research methods for psychologists. London: Elsevier.

Freud, S. (1947). Het ik in de psigologie der massa. Amsterdam: Wereld bibliotheek N.V.
Gilgen, A.R. (1995). Chaos theory in psychology. New York: Greenwood Press.

Glass, L., \& Mackey, M.C. (1988). From clocks to chaos: The rythms of life. New York: Princeton.

Gould, L.J., Stapley, L.F., \& Stein, M. (2004). Experiential learning in organisations. Applications of the Tavistock group relations approach. London: Karnac.

Henning, S. (2009). Towards a system psychodynamic model of psychological wellness. Unpublished DPhil thesis, University of South Africa, Pretoria, South Africa.

Hinshelwood, R.D., \& Skogstad, W. (2005). Observing organisations. Anxiety, defence and culture in health care. London: Routledge.

Huffington, C., Armstrong, A., Halton, W., Hoyle, L., \& Pooley, J. (2004). Working below the surface. The emotional life of contemporary organisations. London: Karnac.

Janov, A. (1991). The new primal scream: primal therapy twenty years on. London: Abacus Books.

Jung, C.G. (1950). CW 18: The symbolic life. New York: Bollingen series.

Jung, C.G. (1960). On the nature of the Psyche. New York: Bollingen series.

Keeny, B.P. (1983). Aesthetics of change. New York: Guilford.

Kets de Vries, M.F. (2007). The Happiness Equation. Lincoln: iUniverse.

Klein, M. (1975). Envy and Gratitude and other works. New York: Delacorte Press.

Lopez, S.H. (2008). Positive psychology: exploring the best in people. London: Praeger perspectives.

Lowman, R.L. (2002). The handbook of organisational consulting psychology. San Francisco: Jossey-Bass.

Mandelbrot, B.B. (2005). The (mis)behaviour of markets: a fractal view of risk, ruin and reward. London: Profile books.

McCormick, D.W., \& White, J. (2000). Using one's self as instrument for organisational diagnosis. Organisational Development Journal, 18(3), 49-62.

Miles, M.B., \& Huberman, A.B. (1994). Qualitative data analysis: An expanded sourcebook. (2nd edn.) London: Sage.

Miller, E.J. (1993). From dependency to autonomy: Studies in organisation and change. London: Free Association Books.

Neumann, J.E., Kellner, K., \& Dawson-Shepherd, A. (1997). Developing organisational consultancy. London: Routledge.

O'Connor, W., \& Lubin, B. (1990). Ecological approaches to clinical and community psychology. Miami: Robert Krieger.

Patton, M.Q. (1990). Qualitative evaluation and research methods. New Bury Park: Sage.

Peterson, C., \& Seligman, M.E.P. (2004). Character strengths and virtues: a handbook and classification. New York: Oxford University Press.

Pirsig, R.M. (1999). Zen and the art of motorcycle maintenance. London: Vintage.

Schneider, M.S. (1994). A beginners' guide to constructing the Universe: The Mathematical archetypes of nature, art and science. New York: HarperPerennial.

Snyder, C.R., \& Lopez, S.J. (2005). Handbook of Positive Psychology. New York: Oxford University Press.

Stacey, R.D. (2003). Strategic management and organisational dynamics: the challenge of complexity. (4th edn.). Harlow: Pearson Education.

Stapley, L.F. (2006a). Global dynamics at the dawn of 2006. Organisational and Socia Dynamics, 6(1), 111-142.

Stapley, L.F. (2006b). Individuals, groups and organizations beneath the surface. London: Karnac.

Stapley, L.F., \& Collie, A. (2005). Global dynamics at the dawn of 2005. Organizationa and Social Dynamics, 5(1), 111-133.

Strümpfer, D.J.W. (1995). The origins of health and strength: From 'salutogenesis' to 'fortigenesis'. South African Journal of Psychology, 25(2), 81-89.

Terre Blanche, M., Durrheim, K., \& Painter, D. (2006). Research in practice. Applied methods for the social sciences. Cape Town: UCT Press.

Von Bertalanffy, L. (1973). General Systems Theory. London: Penguin Books.

Wilber, K. (2000). Sex, ecology, spirituality: The spirit of evolution. London: Shambhala.

Winnicot, D.W. (1951). Transitional objects and transitional phenomena. In Through paediatrics to psycho-analysis (pp. 229-242). New York: Basic Books.

Wissing, M.P., \& Van Eeden, C. (1997). Psychological wellbeing: a fortigenic conceptualisation and empirical clarification. Paper presented at the 3rd Annual Congress of the Psychological Society of South Africa, Durban, South Africa, 10-12 September. 